\title{
Assessment of carbonaceous fractions in ambient aerosols at high altitude and lowland urban locations of Kumaon Province, Indian Himalaya
}

\author{
Amit Kumar ${ }^{1,2}$ D $\cdot$ Sachchidanand Singh ${ }^{2} \cdot$ Niraj Kumar $^{3} \cdot$ Narendra Singh $^{4} \cdot$ Krishan Kumar $^{1} \cdot$ Sapna Chourasiya $^{5}$
}

Received: 28 September 2020 / Accepted: 21 December 2020 / Published online: 11 January 2021

(c) The Author(s) $2021 \quad$ OPEN

\begin{abstract}
The present study investigates the characteristics of carbonaceous species like organic carbon (OC) and elemental carbon (EC) in ambient total suspended particulates (TSP) at Bhimtal (high altitude urban, $1413 \mathrm{~m}$ asl) and Pantnagar (lowland urban, $224 \mathrm{~m}$ asl) sites of Kumaon province in Uttarakhand, Indian Himalayan region during winter and summer 20172018. Ambient TSP samples were taken on quartz filters with high volume sampler followed by OC and EC quantification using IMPROVE_thermal optical reflectance protocol. Results showed that distinct seasonal differences in carbonaceous species levels were observed at both sites, while day- and night-time concentrations did not show notable variations. Further, total carbonaceous aerosols (TCA) at Pantnagar were approximately 3.0 and 1.3 times higher than Bhimtal for winter and summer, respectively, where estimated TCA accounted for $~ 30 \%$ to total TSP at both sites. Among quantified eight carbon fractions, OC2 and OC 3 at Bhimtal while EC1 and EC2 at Pantnagar were the most abundant components. The char-EC and soot-EC concentrations showed a similar seasonal pattern where char contributed significantly as $89-90 \%$ to total EC at both sites. The observed OC/EC ratios suggested the formation of secondary organic carbon and char-EC/soot-EC ratios implied biomass burning as major sources for carbonaceous aerosols. Pearson correlation analysis indicated that char-EC showed significant higher correlations with OC and EC than soot-EC which infers different formation mechanisms of char and soot. Most of the carbonaceous parameters exhibited contrasting positive and negative correlations with the boundary layer height, temperature, and solar radiation at Bhimtal and Pantnagar, respectively.
\end{abstract}

Keywords Carbonaceous aerosols · Himalaya · Carbon fractions · Char/soot · Meteorological parameters

\section{Introduction}

In the last few decades, numerous studies have been reported concerning carbonaceous species of ambient aerosols and their impact on local/global climate, atmospheric chemistry, air quality, biodiversity and human health [1-6]. Carbonaceous aerosols are ubiquitous in nature mainly consisted of organic carbon (OC) and elemental carbon (EC) which have significant portions in atmospheric aerosols $[7,8]$. OC comprises a diversity of organic compounds, and their atmospheric sources could be both primary and secondary in origin. Primary OC may release from fossil fuel combustion/biomass burning as fine particulates and mechanical processes of the

Supplementary Information The online version contains supplementary material available at (https://doi.org/10.1007/s42452-020-04010 $-4)$.

Amit Kumar, amit.sagarjnu2@gmail.com |'School of Environmental Sciences, Jawaharlal Nehru University, New Delhi 110067, India. ${ }^{2}$ CSIR-National Physical Laboratory, Environmental Science and Biomedical Metrology Division, New Delhi 110012 , India. ${ }^{3} \mathrm{Nawal}$ Agro and Plantation Pvt. Limited, Ranchi 834001, India. ${ }^{4}$ Aryabhatta Research Institute of Observational Sciences, Nainital 263001, India. ${ }^{5}$ Satyawati College Evening, University of Delhi, New Delhi 110052, India. 
ecosystem like plant spores and pollens, soil organic matter and decomposed vegetative debris as coarse particulates [9]. Atmospheric chemical reactions between volatile organics and gas-phase precursors through low vapour pressure, optimum temperature and solar radiation are known for secondary OC emissions $[3,10]$. However, EC (similar to graphitic carbon) is exclusively primary in origin and occurred as residues mainly derived from incomplete combustions of biomass and fossil fuels $[4,11]$. These carbonaceous species influence visibility, atmospheric radiative forcing, cloud physics and climatic systems $[12,13]$. It is reported that $\mathrm{OC}$ has both warming and cooling effects on the atmosphere, while EC has warming characteristics and acts as the second most contributing agent after carbon dioxide in enhanced global warming. $\mathrm{OC}$ and $\mathrm{EC}$ both consisted of diverse ranges of carcinogenic and mutagenic compounds which cause morbidity and mortality of cardiovascular and respiratory disorders $[14,15]$.

In recent times, carbonaceous fractions are determined in the aerosol as bulk content of $\mathrm{OC}$ and $\mathrm{EC}$ along with eight carbon sub-fractions like OC1 to OC4, OP (organic pyrolysed carbon) and EC1 to EC3. The quantification of individual substance in $\mathrm{OC}$ fraction at the molecular level is still very challenging due to the complicated molecular structures of carbonaceous aerosols [16]. The variability of spatial/temporal distribution of carbon fractions significantly influences the physico-chemical properties of carbonaceous aerosols $[17,18]$. EC is further classified into two groups, namely char-EC (formed at relatively low combustion temperatures and limited access of air) and soot-EC (formed at higher temperatures via gas phases processes by incomplete combustion) [19]. Nowadays, these eight fractions, char-EC and soot-EC are being used as indicators for source profiling of the carbonaceous aerosols [20-22]. Char-EC and soot-EC possess differences in physical, chemical and optical characteristics; therefore, they influence climate and environment in different ways [8]. Char-EC has the property of strong absorption in the UV region, whereas soot strongly absorbs solar light with little spectral dependence [23].

Significant roles of carbonaceous aerosols on the regional and global atmosphere have received increasing and special attention among the scientific community $[9,24-26]$. The unprecedented urbanization along with rapid commercial and industrial development leads to deterioration of air quality in urban areas worldwide. Several research and reports have been documented which pertains to the determination of carbonaceous aerosols in the urban set-up where commercial, industrial activities and huge transportation networks are occurred [13, 27]. However, limited measurements concerning carbonaceous aerosols have been conducted over urban city/ town/remote location in high altitude regions across the world. Very few studies dedicated to carbonaceous aerosols have been reported from the Indian Himalayan region. The contribution of black carbon to total aerosol optical depth and direct radiative forcing was estimated in detail by Srivastava et al. (2011) over Manora Peak in the Indian Himalayan foothills [28]. Kumar and Attri [29] investigated the role of biomass combustion in carbonaceous aerosols in the western Himalayas and Rajput et al. [30] reported an abundance of carbonaceous aerosols in the foothills of northeast Himalaya [29, 30]. Recently, Sandeep et al. [31] measured OC and EC concentrations for one year over Srinagar, India, an ecologically sensitive semi-urban site in Garhwal Himalayas, and suggested that boundary layer dynamics and anthropogenic activities are responsible for seasonal variations [31]. However, no field campaigns were previously performed regarding comparative study of carbonaceous aerosols in lowland and high altitude regions of Indian Himalayas.

It is thus imperative to examine the sources and load of carbonaceous aerosols in the urbanized location of the mountainous region during different seasons and compare it with the lowland (Tarai) region. Therefore, we investigated the levels of carbonaceous species in total suspended particulates (TSP) at high altitude urban site (Bhimtal) and Tarai area (Pantnagar) in the Kumaon province of the Indian Himalayan region. The primary objectives of the present study include (a) determination of seasonal and day-night characteristics of carbonaceous components in TSP; (b) quantification of eight carbon fractions along with char and soot; (c) source attribution using char and soot ratios; (d) contributions of carbonaceous components to TSP and its comparison with earlier studies and (e) finally correlation analysis among carbonaceous components and meteorological parameters.

\section{Materials and methods}

\subsection{Study area}

Total suspended particulates (TSP) sampling campaign was conducted at two locations at Bhimtal (high altitude urban) and Pantnagar (lowland urban) in the Kumaon province of Uttarakhand, western Himalaya. The geographical locations of the sampling sites are shown in Fig. 1. Bhimtal is the hill station/small town of Kumaon province in the lower Himalayas which is geographically situated at $29.35^{\circ} \mathrm{N}$ and $79.53^{\circ} \mathrm{E}$ with a population of 7722 [32]. It is located approximately $22 \mathrm{~km}$ away from the Nainital city at an altitude of $1413 \mathrm{~m}$ asl and has recently witnessed dramatic urbanization and economic growth in the last two decades. It is bound by a dense forest of oak, pine, and shrubs where the climate is characterized 


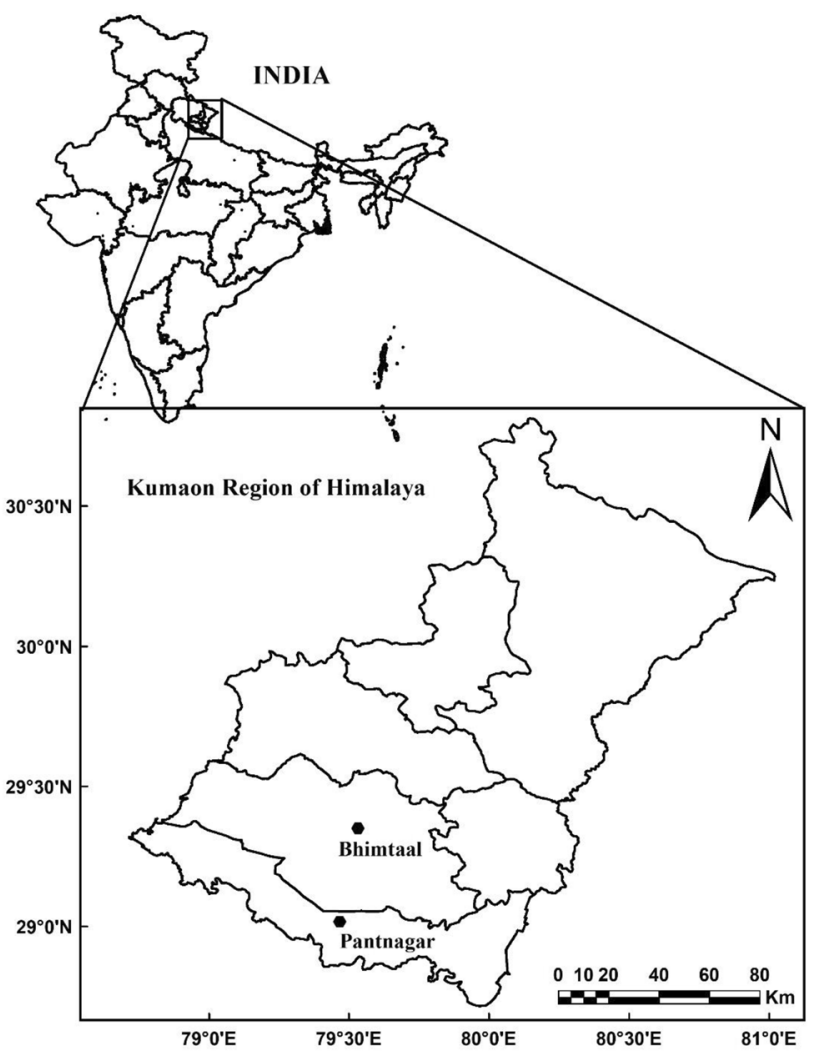

Fig. 1 Map showing the geographical locations of sampling sites at Bhimtal and Pantnagar in Kumaon region, Western Himalaya

by pleasant summers $\left(15-29^{\circ} \mathrm{C}\right)$ and winters $\left(4-18^{\circ} \mathrm{C}\right)$. Due to the belief of holy land in mountainous regions, pilgrimage activities and aesthetic natural beauty, thousands of tourists visit here and go to higher altitudes via this region every year. This has increased anthropogenic activities and energy consumption through fossil fuel burning led to the deterioration of air quality. There were no major industrial activities near or surroundings of the sampling location. The elevation, location, energy consumption, religious activities and prevailing meteorological condition make Bhimtal a unique urban site as compared to other urban regions.

Another sampling site was selected at Pantnagar in Udham Singh Nagar district of Uttarakhand, India. It is geographically located at $29.01^{\circ} \mathrm{N}$ and $79.47^{\circ} \mathrm{E}$ at an elevation of $224 \mathrm{~m}$ asl in the "Tarai" region (lowland urban area) in Himalayan foothills. Pantnagar town with a population of 35,820 , is a mixture of the university campus (G. B. Pant University of Agriculture and Technology) and industrial estate (431 industries spread over 1310 ha of land consisted of food production, electroplating, automobile industries, etc.) [33]. The climate of Pantnagar is characterized by humid sub-tropical conditions and accounted for varying climatic extremes throughout the year. In general, summer and winter temperatures in this region are in the range of $26-42^{\circ} \mathrm{C}$ and $8-15^{\circ} \mathrm{C}$, respectively, with an annual rainfall of $1300-1400 \mathrm{~mm}$. Pantnagar has a flat topography and is also known as a centre of attractions for tourists near its vicinity like Jim Corbett National Park, Nainital, and Mukteshwar.

\subsection{Sampling}

High volume air sampler (Envirotech APM 450, India) was used to collect ambient TSP at both sampling sites with a flow rate of $1.1 \pm 0.1 \mathrm{~m}^{3} /$ minute. TSP samples were collected for five consecutive days during the winter and summer seasons at both sites for daytime (07:00 to 19:00 h) and night-time (19:00 to 07:00 h) periods. At both study sites, sampling was performed during November (2017) and May (2018) for winter and summer seasons, respectively. Twelve hours TSP samples were collected on quartz filters (PALLFLEX ${ }^{\mathrm{TM}}$; 2500 QAT-UP, size: $20.0 \mathrm{~cm}$, $25.4 \mathrm{~cm}$ ). Before sampling, quartz filters were pre-combusted at a temperature of $900{ }^{\circ} \mathrm{C}$ in a muffle furnace to remove any residual carbon or impurities [34]. After sampling, all exposed filter samples were kept in zip-lock plastic bags and stored in a refrigerator until OC and EC analysis to avoid evaporation of deposited VOCs. TSP mass loadings $(\mu \mathrm{g})$ were deduced from gravimetric measurements done before and after sampling using a weighing machine (AD—50 B, ADAIR DUTT Instruments Pvt. Ltd), and corresponding concentrations $\left(\mu \mathrm{g} / \mathrm{m}^{3}\right)$ were evaluated by dividing mass loadings to sampled air volume. Flow rate and duration of the sampling period were used to estimate the volume of air sampled. Quartz filters were equilibrated in a desiccator for $24 \mathrm{~h}$ at constant temperature $\left(23-25^{\circ} \mathrm{C}\right)$ and relative humidity $(40-45 \%)$ for $4-5 \mathrm{~h}$ [35]. Field blank filters were also taken into account by exposing filter paper in the sampler without running the pump for same sampling duration. In order to remove positive sampling artefact, the estimated sample results were corrected by the subtraction of mean values of observed blank concentration $[34,36]$. The precision of the weighing process was $<10 \mu \mathrm{g}$ for the blank filters and $<20 \mu \mathrm{g}$ for the filter samples. All necessary precautions were strictly considered during the handling of quartz filters to avoid any possibility of contamination.

\subsection{Chemical analysis}

TSP quartz filters were analysed for OC and EC quantifications using the DRI model 2001 Thermal/Optical Carbon analyser (Atmoslytic Inc., Calabasas, CA). A small punch aliquot of $0.5 \mathrm{~cm}^{2}$ from each filter was positioned at a quartz tube inside the thermal desorption chamber of the analyser. The analytical procedure consisted of two 
stages of stepwise heating (thermal differentiation) following IMPROVE-A (Interagency Monitoring of Protected Visual Environments) protocol produce four organic carbon fractions and three elemental carbon fractions [18, 37]. OC fractions as $\mathrm{OC} 1, \mathrm{OC} 2, \mathrm{OC} 3$ and $\mathrm{OC} 4$ were volatilized at respective temperatures of $140^{\circ} \mathrm{C}, 280^{\circ} \mathrm{C}, 480^{\circ} \mathrm{C}$ and $580^{\circ} \mathrm{C}$ in a non-oxidizing helium atmosphere. Further, a pyrolysed carbon fraction (OP) was determined when reflected laser light attained its original intensity after oxygen was added to the combustion atmosphere. Moreover, EC fractions as EC1, EC2 and EC3 were produced at $580^{\circ} \mathrm{C}, 740{ }^{\circ} \mathrm{C}$ and $840{ }^{\circ} \mathrm{C}$, respectively, in the presence of $2 \%$ oxygen $/ 98 \%$ helium. After analysis, a datasheet was generated which reports data of eight carbon fractions separately. According to IMPROVE-A protocol, OC is represented as $\mathrm{OC} 1+\mathrm{OC} 2+\mathrm{OC} 3+\mathrm{OC} 4+\mathrm{OP}$, while $\mathrm{EC}$ as $\mathrm{EC} 1+\mathrm{EC} 2+\mathrm{EC} 3-\mathrm{OP}$ [37]. Further, char-EC is determined by $E C 1$ minus $O P$, while soot-EC designates the sum of $E C 2$ and EC3 [21]. The OC/EC analyser is auto-calibrated every day using known concentrations of $\mathrm{CH}_{4}$ before and after sample analysis. Replicate analysis was also carried out for every ten samples run where the difference estimated was smaller than $5 \%$ for the total carbon (TC, OC +EC) and $10 \%$ each for $\mathrm{OC}$ and EC. Detection limits for $\mathrm{OC}$ and $\mathrm{EC}$ were calculated as $0.25 \mu \mathrm{g} / \mathrm{m}^{3}$ and $0.04 \mu \mathrm{g} / \mathrm{m}^{3}$, respectively. OC and EC concentrations were also estimated in blank filters and average blank concentrations have been used to get a correction in the sample results. It is important to note that fraction of carbonate carbon (CC) in the aerosol samples have not been chemically removed for the present study.

\section{Results and discussion}

\subsection{Seasonal and day-/night-time variations of $O C$, $E C$, char-EC and soot-EC}

Twelve hours seasonally averaged and day-night-time atmospheric concentrations of TSP along with different carbonaceous components during the observation period for two studied sites are documented in Table 1. Firstly, it can be seen that the levels of TSP and OC/EC concentrations at Pantnagar (urban, lowland Tarai) site were higher than Bhimtal (urban, high altitude) site. Higher concentration values of TSP and carbonaceous species at Pantnagar could be due to industrial processes and seasonal agricultural practices. Banerjee et al. [38] reported higher pollution at the same site because of the development of industrial estate [38]. The seasonal analysis suggested that TSP and OC/EC concentrations were higher during summer in contrast to winter at Bhimtal while contrasting results at Pantnagar with higher and lower concentrations of these parameters during winter and summer, respectively. At Bhimtal, mean concentrations of TSP/(OC)/(EC) were found to be $89.7 /(12.9) /(3.6) \mu \mathrm{g} / \mathrm{m}^{3}$ and $109 /(18.7) /$ (5.4) $\mu \mathrm{g} / \mathrm{m}^{3}$ for winter and summer, respectively. On the other hand, respective TSP/(OC)/(EC) concentrations at Pantnagar were observed as $224 /(35.3) /(15.6) \mu \mathrm{g} / \mathrm{m}^{3}$ and $180 /(23.1) /(8.8) \mu \mathrm{g} / \mathrm{m}^{3}$ for winter and summer.

The day-to-night-time $(\mathrm{D} / \mathrm{N})$ ratios at Bhimtal for winter and summer were 1.5 and 1.2 for TSP, 1.2 and 1.1 for $\mathrm{OC}$ and 1.3 and 1.0 for EC, respectively. Higher daytime concentrations of $\mathrm{OC}$ and EC at Bhimtal could be attributed to more tourist activities during the daytime. However, irrespective of high night-time TSP concentrations at Pantnagar, the $\mathrm{D} / \mathrm{N}$ ratios for winter and summer were 1.2 and 1.2 for $\mathrm{OC}$ and 1.2 and 1.1 for EC, respectively. Higher TSP concentrations during night-time than daytime at

Table 1 Statistical summary of seasonal and day-/night-time concentrations of different TSP components $\left(\mu \mathrm{g} / \mathrm{m}^{3}\right)$ at Bhimtal and Pantnagar

\begin{tabular}{|c|c|c|c|c|c|c|c|c|}
\hline & \multicolumn{4}{|l|}{ Bhimtal } & \multicolumn{4}{|l|}{ Pantnagar } \\
\hline & \multicolumn{2}{|l|}{ Winter } & \multicolumn{2}{|l|}{ Summer } & \multicolumn{2}{|l|}{ Winter } & \multicolumn{2}{|l|}{ Summer } \\
\hline & $A v g \pm S D$ & $\mathrm{D} / \mathrm{N}$ & $A v g \pm S D$ & $\mathrm{D} / \mathrm{N}$ & $A v g \pm S D$ & $\mathrm{D} / \mathrm{N}$ & $A v g \pm S D$ & $\mathrm{D} / \mathrm{N}$ \\
\hline TSP & $89.7 \pm 24.6$ & $103 / 70.1$ & $109 \pm 18.1$ & $120 / 98.6$ & $224 \pm 49.8$ & $200 / 247$ & $180 \pm 36.9$ & $173 / 188$ \\
\hline OC & $12.9 \pm 4.4$ & $14 / 11.8$ & $18.6 \pm 3.4$ & $19.5 / 17.7$ & $35.3 \pm 4.0$ & $37.9 / 32.7$ & $23.1 \pm 4.5$ & $25.2 / 21.1$ \\
\hline EC & $3.6 \pm 1.0$ & $4.1 / 3.1$ & $5.4 \pm 1.3$ & $5.5 / 5.3$ & $15.6 \pm 2.2$ & $17.1 / 14$ & $8.8 \pm 3.0$ & $9.4 / 8.3$ \\
\hline Char-EC & $3.2 \pm 1.0$ & $3.8 / 2.7$ & $4.9 \pm 1.2$ & $5.0 / 4.8$ & $13.7 \pm 2.3$ & $15.2 / 12.2$ & $7.9 \pm 3.0$ & $8.4 / 7.5$ \\
\hline Soot-EC & $0.4 \pm 0.05$ & $0.4 / 0.4$ & $0.5 \pm 0.1$ & $0.5 / 0.4$ & $1.8 \pm 0.4$ & $1.9 / 1.8$ & $0.9 \pm 0.2$ & $0.9 / 0.8$ \\
\hline $\mathrm{OM}$ & $20.6 \pm 7.0$ & $22.3 / 18.9$ & $29.8 \pm 5.5$ & $31.3 / 28.3$ & $56.5 \pm 6.4$ & $60.7 / 52.4$ & $37.0 \pm 7.2$ & $40.3 / 33.7$ \\
\hline EM & $4.0 \pm 1.1$ & $4.6 / 3.4$ & $5.9 \pm 1.4$ & $6 / 5.8$ & $17.1 \pm 2.4$ & $18.8 / 15.4$ & $9.7 \pm 3.3$ & $10.3 / 9.1$ \\
\hline TCA & $24.2 \pm 7.7$ & $26.4 / 22$ & $35.2 \pm 6.6$ & $36.7 / 33.6$ & $72.1 \pm 8.4$ & $77.6 / 66.4$ & $45.8 \pm 9.7$ & 49.7/42 \\
\hline
\end{tabular}

SD Standard deviation, $D$ day, N night, OMorganic matter, EM elemental matter, TCA total carbonaceous aerosols 
the lowland urban region of Pantnagar suggested mixing height plays an important role in the diurnal variation. TSP was observed to be low during daytime when mixing height was higher (ranged from 417 to $1081 \mathrm{~m}$ ). In contrast, higher concentrations occurred during night-time when mixing height was lower in the range of $180-458 \mathrm{~m}$. Higher night-time concentrations could be associated with trapping of TSP due to the lowering of mixing height [39]. Similar higher concentrations are generally noticed during the night-time (than daytime) in urban areas $[27,40]$. The temporal variability of TSP along with carbonaceous species for two studied sites is shown in Fig. 2.

Along with $\mathrm{OC}$ and $\mathrm{EC}$, other carbonaceous components like Total Carbonaceous Aerosols (TCA), Organic Matter (OM) and Elemental Matter (EM) in ambient TSP for two studied sites are also reported (Table 1). The quantity of OM was estimated by the multiplication of observed OC concentrations with a factor of 1.6 [41], while EM amounts have been estimated by multiplying the EC concentrations with 1.1 [42]. Further, TCA in the atmosphere is evaluated by the summation of $\mathrm{OM}$ and $\mathrm{EC}(\mathrm{TCA}=\mathrm{OC} \times 1.6+\mathrm{EC})$ [43]. The conversion factors for $\mathrm{OC}$ to $\mathrm{OM}$ have a wide range of values (1.2-2.1) reported in previous literature [44]. The lower values of the conversion factors (1.2-1.4) are used for the organic aerosol having lower SOA fraction; however, higher values were considered for aerosols with higher SOA fractions. Similar to OC/EC concentrations, Pantnagar exhibited higher mean values of OM, EM and TCA as compared to the values of Bhimtal. The concentration ratios of Pantnagar to Bhimtal showed for winter and summer were 2.7 and 1.2 for $\mathrm{OM}, 4.3$ and 1.6 for $\mathrm{EM}$ and 3.0 and 1.3 for TCA, respectively. At Bhimtal, the mean values of OM, EM and TCA were noted to be higher as 1.7, 1.5 and 1.5 times during summer in contrast to winter. However, Pantnagar exhibited contrasting respective results as 1.5 , 1.8 and 1.6 times higher during winter as compared to summer.

The observed variations of TSP and carbonaceous species at two selected sites could be explained by the combined phenomenon of emission sources (biomass burning, coal combustion and vehicular exhaust), their emission rates and prevailing meteorological conditions. In the context of high altitude Bhimtal site, seasonal and day/ night variations of TSP and OC/EC concentrations can be understood by the phenomenon of vertical movement of planetary boundary layer and distant transport [45]. Summer time exhibited higher values of pollutants because of an increase in convective mixing and extent of convective boundary layer due to more surface heating, which resulted in a conducive environment for the upliftment of aerosols from the valley region [46]. Besides this, higher summer concentrations could also be due to an increase in
Fig. 2 Temporal variations of TSP along with OC, EC and TCA concentrations $\left(\mu \mathrm{g} / \mathrm{m}^{3}\right)$ in Bhimtal and Pantnagar

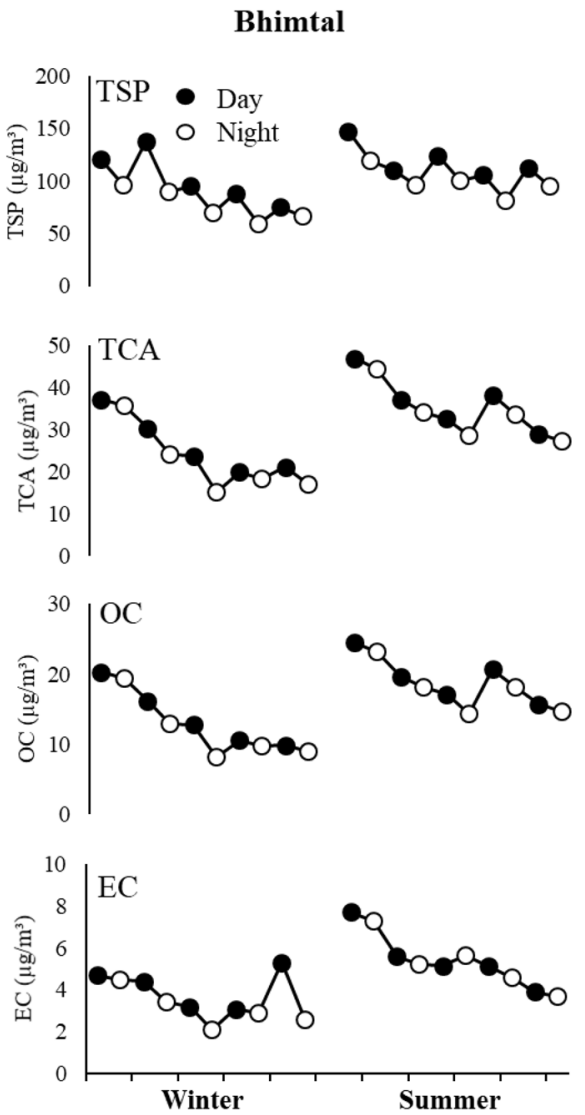

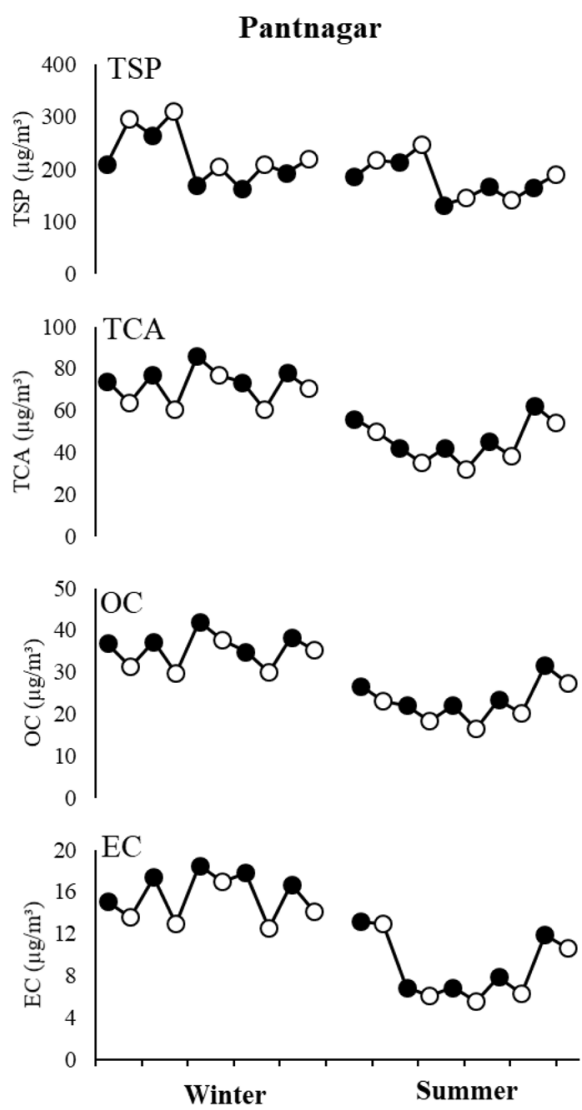

SN Applied Sciences 
vehicular emissions due to tourism and pilgrimage activities. In the case of Pantnagar, TSP and OC/EC exhibited higher and lower concentrations during winter and summer, respectively, similar to the observed results of plain urban areas [14, 27]. Besides enhanced fuel consumption, formation of the inversion layer and stable conditions during the winter period resulted into the trapping of carbonaceous aerosols could also be the main reasons for higher concentrations during winter [23]. Further, vertical mixing and increased planetary boundary layer could be associated with lower carbonaceous pollutants during summer.

The backward air trajectory analysis over Bhimtal and Pantnagar could also explain the wind patterns and long-range transport of pollutants. $120 \mathrm{~h}$ air mass backtrajectory plots at three different heights $(500 \mathrm{~m}, 1000 \mathrm{~m}$ and $1500 \mathrm{~m}$ above ground level) have been plotted using the HYSPLIT model, developed by NOAA (http:// ready. arl.noaa.gov/HYSPLIT.php). The representative air mass back-trajectories for each season over Bhimtal and Pantnagar are shown in Fig. 3a, b. It can be seen that winters are dominated by south and south-westerly air masses, which passes through the central part of India prior to entering in high altitude Bhimtal region. In contrast, transported air masses during summer largely came from the northeast region pass over the Indo-Gangetic plain before reaching Bhimtal. Higher summer-time concentrations of carbonaceous aerosols at Bhimtal are attributed to coming winds from the Indo-Gangetic plain (highly polluted region). At Pantnagar, air masses were observed to be mostly arriving from north/north-west directions originated from Pakistan and Afghanistan during winter and pass through agricultural states of Himachal Pradesh, Punjab and Haryana before entering to the receptor site. Agricultural residues burning practices in the neighbouring states could be associated with higher carbonaceous aerosols during the winter season. Pantnagar experienced shorter trajectories
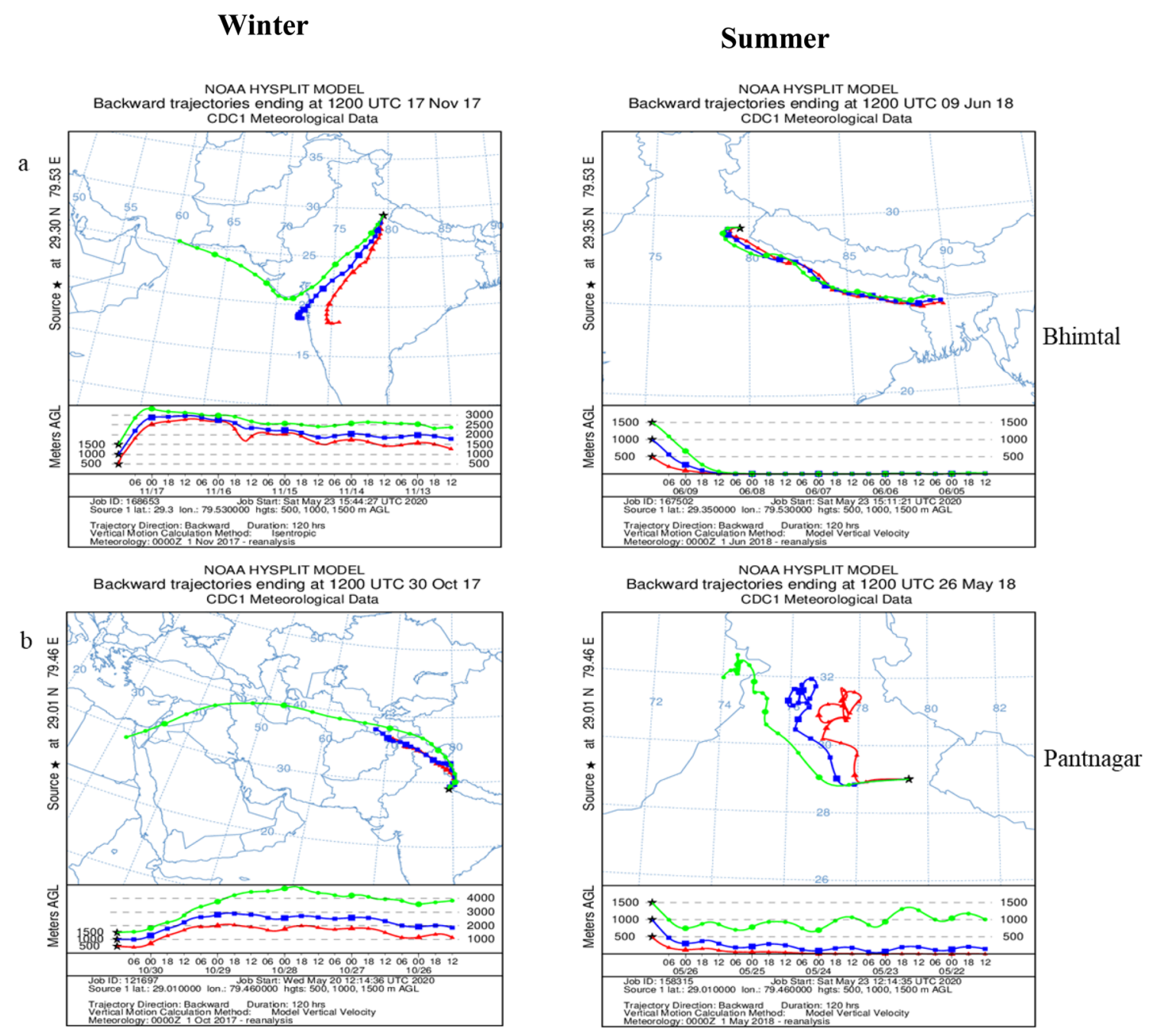

Fig. 3 Representative air mass back-trajectories over sampling sites a Bhimtal and $\mathbf{b}$ Pantnagar during winter and summer seasons 
during summer infers dominance of local pollution along with distant transport.

\subsection{Characterization of eight carbon fractions at studied sites}

The present section deals with the occurrence of different carbon fractions at two studied sites. The analytical procedure of IMPROVE TOR protocol consisted of different evaporation or oxidation temperatures for carbon fractions (OC1-OC4, OP and EC1-EC3) which have unique characteristics and emission sources [37]. Source profiling of carbonaceous aerosols is done based on the abundance of carbon in each of these eight carbon fractions $[1,19]$. Based on the previous literature, $\mathrm{OC} 1$ and EC1 infer biomass burning, OC2 and OC 3 might be emitted from SOC and biomass burning sources, $\mathrm{OC} 4, \mathrm{EC} 2$ and $\mathrm{EC} 3$ designate coal combustions and vehicular emissions and OP could be an indication of increased water-soluble organic carbon [19]. According to Zhang et al. (2012), higher contents of OC3 and OC4 reflect road dust as pollution sources [4].

The percentage seasonal contribution of $O C$ and EC fractions in TSP for two studied sites is shown in Fig. 4. These carbon fractions at Bhimtal accounted in the order of OC2 $(28.9 \%)>$ OC3 $(21.1 \%)>E C 1(20.2 \%)>O C 4$ $(11.8 \%)>\mathrm{OP}(9.0 \%)>\mathrm{OC} 1(6.9 \%)>\mathrm{EC} 2(1.7 \%)>\mathrm{EC} 3(0.6 \%)$. On the other hand, the average contributions of these fractions at Pantnagar were ranked in the following order: EC1 $(25.5 \%)>$ OC2 $(24.7 \%)>$ OC3 $(21.5 \%)>$ OP $(11.6 \%)>$ OC4 $(8.1 \%)>$ OC1 $(5.7 \%)>$ EC2 (2.4\%) > EC3 (0.8\%). OC2 and OC3 were the main carbon fractions in Bhimtal, while $\mathrm{EC} 1$ and $\mathrm{OC} 2$ were the prevalent carbonaceous species in Pantnagar. Therefore, fractions contribution at the two sites suggested the occurrence of major sources like vegetative burning, coal combustion and vehicular emissions.

In the present study, observed contributions of four organic carbon fractions $(\mathrm{OC} 1, \mathrm{OC} 2, \mathrm{OC} 3$ and OC4) to TC

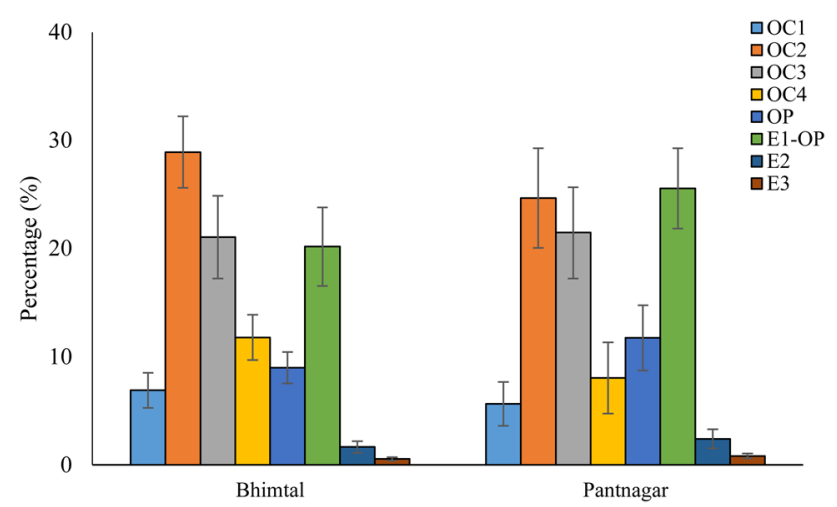

Fig. 4 Percentage contributions of eight carbon fractions to total carbon at studied sites were noted to be higher than urban area of Costa Rica, Central America which ranged from $0.9 \%$ to $19.8 \%$ in $\mathrm{PM}_{10}$ and $1.5 \%$ to $16.6 \%$ in $\mathrm{PM}_{2.5}$, respectively [10]. Similarly, the average abundance of OC1 to OC4 was also observed to be lower (4.3-19.9\%) in the Pearl River Delta Region, China [1]. The study carried out in urban areas of Hanoi, Vietnam has suggested $\mathrm{OC} 3$ and $E C 1$ were predominant in $\mathrm{PM}_{10}$ and $\mathrm{PM}_{2.5}$, while $\mathrm{OC} 3$ and $\mathrm{OC} 2$ were the prevailing carbonaceous fractions of $\mathrm{PM}_{0.1}$ [11]. The EC2 and EC3 contributions of the present study were comparable with the contributions reported in Tianjin, China, and lower in the Pearl River Delta Region, China $[1,3]$.

\subsection{Char- and soot-EC variations and source identification using char-EC/soot-EC ratios}

Based on the analytical methods, EC is also categorized into two groups commonly known as char-EC and soot-EC which have different physico-chemical and optical properties. In general, char-EC is mainly derived as residues from incomplete combustion or heating of carbonaceous matter in limited access of air, while soot-EC is formed from gas-particle re-condensation at higher temperature burning process $[19,21]$. The larger particle size of charEC makes higher rate of deposition which indicated local combustion emissions and the smaller size of soot-EC favours long-range transport resulted into a longer lifetime [47].

The average concentrations of char-EC and soot-EC at Bhimtal were $3.23 \pm 1.02 \mu \mathrm{g} / \mathrm{m}^{3}$ and $0.38 \pm 0.05 \mu \mathrm{g} / \mathrm{m}^{3}$ (winter) and $4.92 \pm 1.97 \mu \mathrm{g} / \mathrm{m}^{3}$ and $0.47 \pm 0.11 \mu \mathrm{g} / \mathrm{m}^{3}$ (summer), respectively. However, respective concentrations of analogue parameters at Pantnagar were $13.7 \pm 2.3 \mu \mathrm{g} / \mathrm{m}^{3}$ and $1.82 \pm 0.45 \mu \mathrm{g} / \mathrm{m}^{3}$ (winter) and $7.9 \pm 3.0 \mu \mathrm{g} / \mathrm{m}^{3}$ and $0.88 \pm 0.18 \mu \mathrm{g} / \mathrm{m}^{3}$ (summer). Overall, char-EC and soot-EC at Pantnagar were approximately 2.7 and 9.6 times higher than the Bhimtal. The observed lower soot-EC levels at both sites indicated less influence of vehicular and industrial emissions. Seasonal variations of char-EC and sootEC may be attributed to differences in fuel combustions and meteorological factors (mixing height, temperature, etc.) [21]. Higher mixing height during summer favours the dispersion phenomenon resulting in the lowering of pollutant concentrations.

In the previous, a quantitative assessment of OC/EC mass ratios was used to identify the carbonaceous sources $[1,48]$. OC/EC ratio method is not widely accepted now due to some of the limitations as it is influenced by photochemical reactivity and secondary organic aerosol (SOA) formation. In contrast, char-EC/soot-EC is considered as an effective tool than OC/EC ratios to infer primary carbonaceous source because they avoid the great bias of dependency on SOA [23]. Cao et al. [20] reported char-EC/ 
Table 3 One-way ANOVA of seasonal and day-/night-time variability in TSP and carbonaceous components at studied sites

\begin{tabular}{lllllllll}
\hline Sampling sites & Comparison criteria & TSP & OC & EC & Char-EC & Soot-EC & OC/EC & Char/soot \\
\hline Bhimtal & Between seasons & $4.1^{\mathrm{a}}\left(0.06^{\mathrm{b}}\right)$ & $10.6(0.00)$ & $11.5(0.00)$ & $11.4(0.00)$ & $4.9(0.03)$ & $0.08(0.77)$ & $8.9(0.00)$ \\
& Between day and night & $7.2(0.01)$ & $0.9(0.37)$ & $0.9(0.35)$ & $0.9(0.34)$ & $0.2(0.63)$ & $0.03(0.86)$ & $5.8(0.02)$ \\
Pantnagar & Between seasons & $4.9(0.04)$ & $41.1(0.00)$ & $32.8(0.00)$ & $23.8(0.00)$ & $37.4(0.00)$ & $8.3(0.00)$ & $4.6(0.04)$ \\
& Between day and night & $2.2(0.15)$ & $2.0(0.17)$ & $1.2(0.29)$ & $1.8(0.3)$ & $0.2(0.68)$ & $0.002(0.96)$ & $0.001(0.96)$ \\
Averaged of two sites & Between sites & $21.6(0.00)$ & $17.7(0.00)$ & $16.2(0.00)$ & $51.4(0.00)$ & $106(0.00)$ & $39.7(0.00)$ & $3.7(0.06)$ \\
\hline
\end{tabular}

${ }^{a}$ Fvalue;

${ }^{b} p$ value

Table 4 Comparison of OC, EC, char-EC, soot-EC, OC/EC and char/soot measurements $\left(\mu \mathrm{g} / \mathrm{m}^{3}\right)$ in present study with cities across the world

\begin{tabular}{|c|c|c|c|c|c|c|c|c|}
\hline Reference & Location & Size fractions & $\mathrm{OC}$ & EC & Char-EC & Soot-EC & OC/EC & Char/soot \\
\hline \multirow[t]{2}{*}{ Present study } & Bhimtal (high altitude urban) & TSP & 15.6 & 4.5 & 4.1 & 0.4 & 3.5 & 10.3 \\
\hline & Pantnagar (lowland semi-urban) & TSP & 29.2 & 12.2 & 10.8 & 1.4 & 2.4 & 7.7 \\
\hline Kaushal et al. [53] & Dharamshala, India (high altitude) & $\mathrm{PM}_{10}$ & 5.0 & 2.5 & 2.1 & 0.4 & 2 & 5.3 \\
\hline Sandeep et al. [31] & Srinagar, India (high altitude) & $\mathrm{PM}_{2.5}$ & 15.3 & 5.2 & - & - & 2.9 & - \\
\hline Kumar and Attri [29] & Kangra, India (high altitude) & $\mathrm{PM}_{10}$ & 13.5 & 5.1 & 5.0 & 0.19 & 2.6 & 26.3 \\
\hline Carrico et al. [50] & Langtang, Nepal (high altitude) & $\mathrm{PM}_{2.5}$ & 2.0 & 0.38 & - & - & 5.3 & - \\
\hline Li et al. [54] & Jiangxi, China (high altitude) & $\mathrm{PM}_{2.5}$ & 3.8 & 1.3 & 0.91 & 0.36 & 2.9 & 2.5 \\
\hline Tanner et al. [51] & Tennessee valley, USA & $\mathrm{PM}_{2.5}$ & 3.3 & 0.55 & - & - & 6 & - \\
\hline Bisht et al. [27] & Delhi, India (urban) & $\mathrm{PM}_{2.5}$ & 37.7 & 7.8 & - & - & - & - \\
\hline Han et al. [24] & Xian, China (urban) & $\mathrm{PM}_{2.5}$ & 38.6 & 8.4 & 6.9 & 1.6 & 4.6 & 4.3 \\
\hline Kim et al. [23] & Saimata, Japan (urban roadside) & $\mathrm{PM}_{2.5}$ & 5.5 & 2.9 & 2.7 & 0.3 & 1.9 & 9 \\
\hline Cao et al. [52] & Shanghai, China (urban) & TSP & 10.1 & 2.5 & 1.7 & 0.7 & 4.0 & 2.4 \\
\hline Zhan et al. [8] & Huangshi, China (urban industrial) & $\mathrm{PM}_{10}$ & 22 & 6.2 & 5.3 & 0.9 & 3.5 & 5.9 \\
\hline Zhu et al. [22] & Xuenshan, Taiwan (urban tunnel) & $\mathrm{PM}_{2.5}$ & 23.9 & 18.9 & 18.1 & 0.8 & 1.3 & 22.6 \\
\hline
\end{tabular}

\subsection{Correlations among carbonaceous components and meteorological parameters}

Correlation analysis was performed among TSP mass, carbonaceous components and meteorological parameters for two studied sites during the observation period and is presented in Table 5. A significant positive correlation between $\mathrm{OC}$ and EC was observed at Bhimtal $(r=0.82)$ and Pantnagar $(r=0.94)$ suggested the combination of common combustion sources for carbonaceous species. Higher correlations were similar to those found in reported results of previous studies [21,41]. As compared to soot-EC, char-EC was highly correlated with TC, OC and EC at both sampling sites which indicated different formation mechanisms for char and soot. It is also concluded that emissions sources of soot-EC could be different from OC and char-EC. Among the carbonaceous components, char-EC showed the strongest correlation with $\mathrm{EC}$ at both sites which were consistent with dominated char-EC of $90 \%$ and $88.5 \%$ contributions to total EC at Bhimtal and Pantnagar, respectively. It is suggested that the occurrence of common burning practices like biomass burning and residential heating. The moderate correlation between soot-EC and EC implied that variations in EC concentrations were also considerably influenced by soot-EC. The correlation between char-EC and soot-EC at both sites were found to be weaker than those between $O C$ and EC. The occurrence of no correlations between OC/EC and char-EC/soot-EC at Bhimtal suggested source variations for carbonaceous aerosols emissions, while Pantnagar exhibited anti-correlation between them.

The association between EC and char-EC, EC and soot$E C$ and soot-EC and char-EC using regression plots at both sites is illustrated in Fig. 5 . It can be seen that char$\mathrm{EC}$ showed the strongest correlation with $\mathrm{EC}$ at both sites which were consistent with observation results conducted in previous studies $[23,24]$. However, soot-EC exhibited moderate correlations with EC at Bhimtal $\left(r^{2}=0.65\right)$ and weak correlations at Pantnagar $\left(r^{2}=0.36\right)$. Char-EC vs sootEC showed weaker correlations as $r^{2}=0.60$ (Bhimtal) and $r^{2}=0.32$ (Pantnagar). Poor correlations at Pantnagar suggested mixed sources of biomass burning, coal combustion and vehicular emissions. 
Table 5 Pearson correlation analysis among observed carbonaceous components in TSP and meteorological parameters

\begin{tabular}{|c|c|c|c|c|c|c|c|c|c|c|c|c|}
\hline & $\mathrm{TC}$ & OC & $\mathrm{EC}$ & OC/EC & Char-EC & Soot-EC & Char/soot & PBL & SR & Temp & WS & $\mathrm{RH}$ \\
\hline \multicolumn{13}{|l|}{ Bhimtal } \\
\hline $\mathrm{TC}$ & 1.00 & & & & & & & & & & & \\
\hline OC & $0.99^{* *}$ & 1.00 & & & & & & & & & & \\
\hline $\mathrm{EC}$ & $0.89^{* *}$ & $0.82^{* *}$ & 1.00 & & & & & & & & & \\
\hline OC/EC & 0.10 & 0.23 & -0.36 & 1.00 & & & & & & & & \\
\hline Char-EC & $0.89^{* *}$ & $0.82^{* *}$ & $0.98^{* *}$ & -0.36 & 1.00 & & & & & & & \\
\hline Soot-EC & $0.68^{* *}$ & $0.62^{* *}$ & $0.80^{* *}$ & -0.36 & $0.77^{* *}$ & 1.00 & & & & & & \\
\hline Char/soot & -0.02 & -0.01 & -0.04 & 0.05 & 0.01 & -0.60 & 1.00 & & & & & \\
\hline PBL & 0.41 & 0.41 & 0.37 & 0.01 & 0.35 & 0.35 & -0.10 & 1.00 & & & & \\
\hline SR & $0.52^{*}$ & $0.51^{*}$ & $0.48^{*}$ & -0.01 & $0.45^{*}$ & $0.55^{*}$ & -0.29 & 0.89 & 1.00 & & & \\
\hline Temp & $0.61^{* *}$ & $0.60^{* *}$ & $0.57^{* *}$ & 0.01 & $0.54^{*}$ & $0.70^{* *}$ & -0.43 & $0.81^{* *}$ & $0.92^{* *}$ & 1.00 & & \\
\hline WS & -0.22 & -0.20 & -0.24 & 0.05 & -0.26 & -0.07 & -0.21 & $0.55^{*}$ & 0.32 & 0.28 & 1.00 & \\
\hline $\mathrm{RH}$ & 0.06 & 0.03 & 0.14 & -0.19 & 0.13 & $0.45^{*}$ & $-0.62^{* *}$ & $-0.54^{*}$ & -0.26 & -0.10 & -0.38 & 1.00 \\
\hline \multicolumn{13}{|l|}{ Pantnagar } \\
\hline TC & 1.00 & & & & & & & & & & & \\
\hline OC & $0.99^{* *}$ & 1.00 & & & & & & & & & & \\
\hline $\mathrm{EC}$ & $0.97^{* *}$ & $0.94^{* *}$ & 1.00 & & & & & & & & & \\
\hline OC/EC & $-0.72^{* *}$ & $-0.63^{* *}$ & $-0.85^{* *}$ & 1.00 & & & & & & & & \\
\hline Char-EC & $0.97^{* *}$ & $0.93^{* *}$ & $0.99^{* *}$ & $-0.85^{* *}$ & 1.00 & & & & & & & \\
\hline Soot-EC & $0.60^{* *}$ & $0.59^{* *}$ & $0.60^{* *}$ & -0.44 & $0.56^{* *}$ & 1.00 & & & & & & \\
\hline Char/soot & $0.70^{* *}$ & $0.66^{* *}$ & $0.72^{* *}$ & $-0.70^{* *}$ & $0.76^{* *}$ & -0.08 & 1.00 & & & & & \\
\hline PBL & -0.33 & -0.30 & -0.36 & 0.40 & -0.36 & -0.18 & -0.25 & 1.00 & & & & \\
\hline SR & $-0.57^{* *}$ & $-0.56^{*}$ & $-0.57^{* *}$ & $0.47^{*}$ & $-0.57^{* *}$ & -0.37 & -0.35 & 0.87 & 1.00 & & & \\
\hline Temp & $-0.62^{* *}$ & $-0.61^{* *}$ & $-0.62^{* *}$ & $0.49^{*}$ & $-0.61^{* *}$ & -0.39 & -0.39 & $0.85^{* *}$ & $0.98^{* *}$ & 1.00 & & \\
\hline WS & $-0.53^{*}$ & $-0.54^{*}$ & $-0.49^{*}$ & 0.28 & $-0.48^{*}$ & $-0.49^{*}$ & -0.14 & $0.56^{* *}$ & $0.62^{* *}$ & $0.66^{* *}$ & 1.00 & \\
\hline $\mathrm{RH}$ & $0.48^{*}$ & $0.46^{*}$ & $0.50^{*}$ & $-0.48^{*}$ & $0.50^{*}$ & 0.35 & 0.30 & $-0.79 * *$ & $-0.94^{* *}$ & $-0.91 * *$ & 0.59 & 1.00 \\
\hline
\end{tabular}

PBL Planetary boundary layer, SR solar radiation, Temp temperature, WS wind speed, $R H$ relative humidity ${ }^{*} p<0.05,{ }^{* *} p<0.01$ (correlation coefficient and significance test).

Besides the emission sources, the occurrence of carbonaceous components in any region is also dependant on prevailing meteorological conditions. Meteorological data set like planetary boundary layer (PBL), temperature $(\mathrm{T})$, solar radiation (SR), wind speed (WS) and relative humidity $(\mathrm{RH})$ during the observed period have been obtained from ERA-5 reanalysis data set, developed by the ECMWF (https://cds.climate.copernicus.eu/cdsapp\#!/home). At Bhimtal, carbonaceous components showed weak to moderate positive correlations $(p<0.01)$ with meteorological variables $T>S R>P B L$. The positive correlations of carbonaceous components with PBL suggested higher concentrations during daytime with an increase in PBL. The atmospheric boundary layer stays far below the observation site during the night-time. The strong convective motions formed in the valley regions results into vertical transport of pollutants through upslope winds favours the higher concentrations during daytime. In contrast, nighttime concentrations are observed to be lower could be due to deepening in PBL. Further, higher temperature and solar radiation along with low wind speed during daytime favour the increased carbonaceous concentrations. Our results are consistent with the observed meteorological association at the high altitude site of Manora Peak [55]. In contrast, Pantnagar exhibited weak to moderate negative correlations $(p<0.01)$ for carbonaceous components with meteorological parameters T $>$ SR $>$ PBL. Pantnagar is a lowland region having flat topography in the vicinity of the Himalayan foothills which does not show phenomena like mountain-valley convective motion and vertical movement of atmospheric pollutants. The good negative correlations of carbonaceous components with $\mathrm{PBL}, \mathrm{T}$ and SR suggested lower concentrations during the daytime could be attributed to increased dispersion and dilution phenomenon due to elevated PBL. Similar results of inverse relationships of carbonaceous components at Pantnagar are in agreement with the other low-altitude urban sites [27, 56]. WS is known for the characteristics of cleanup function which influence the occurrence of pollutant concentrations [56]. Weak negative correlations 


\section{Bhimtal}

$\mathbf{a}$

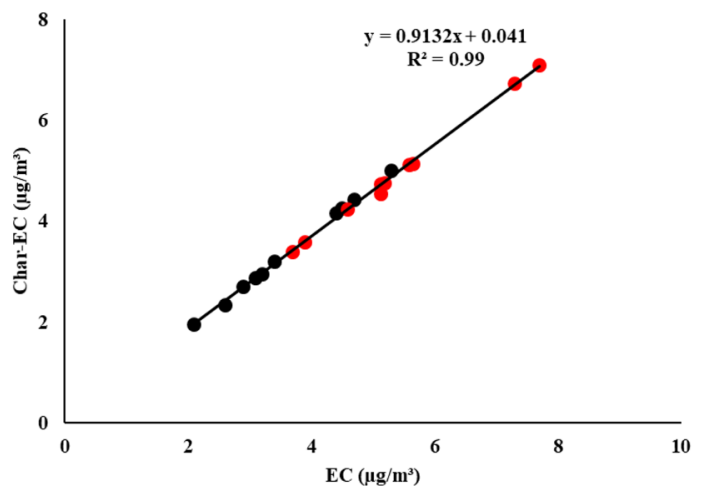

$\mathbf{b}$

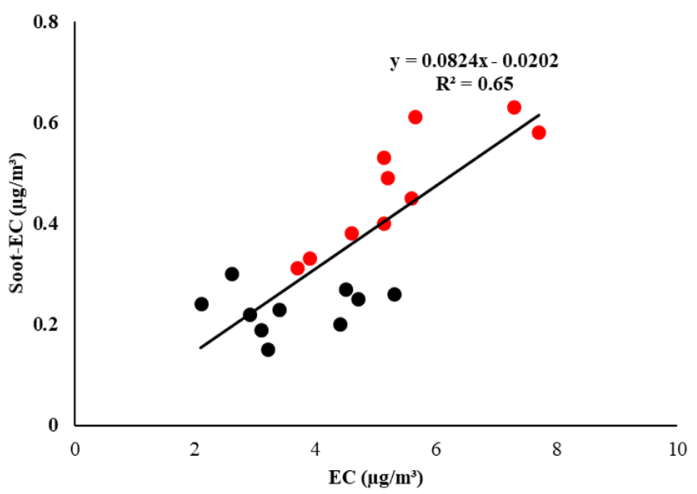

c

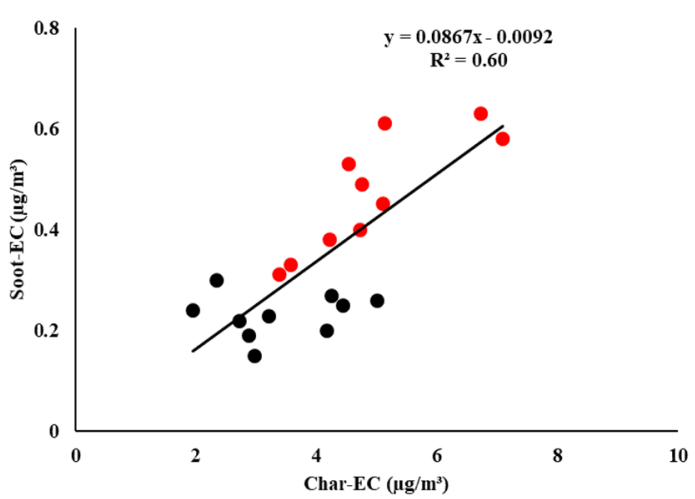

Pantnagar
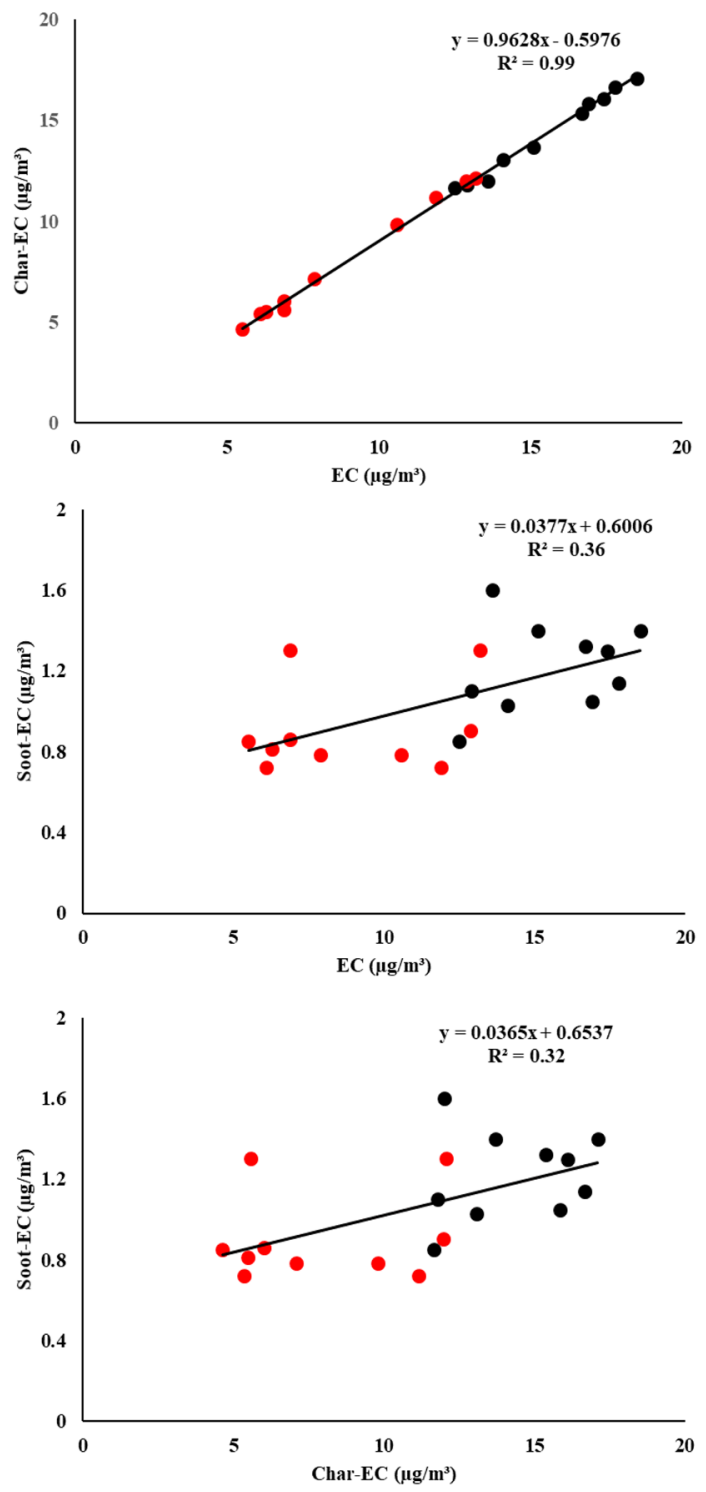

Fig. 5 Regression plots between $\mathbf{a} E C$ and char-EC, $\mathbf{b}$ EC and soot-EC and $\mathbf{c}$ char-EC and soot-EC at Bhimtal and Pantnagar

were found for OC and EC with WS at Bhimtal. However, good negative correlations were observed for OC and EC with WS suggested the cleanup function of wind at Pantnagar. No significant correlation was observed for most of the carbonaceous components with $\mathrm{RH}$ at Bhimtal, while moderate positive correlations were found at Pantnagar.

\section{Conclusions}

Carbonaceous components of particulates are considered as one of the important agents for influencing atmospheric chemistry and local/regional air quality. This work reports the first measurements in Bhimtal (high altitude urban) and Pantnagar (lowland urban) regions which cover the comparative assessment of different eight carbon fractions in carbonaceous aerosols, correlations among carbonaceous species and meteorological factors along with source attribution using char/soot ratio. Distinct seasonal differences of TSP, OC, EC and TCA concentrations were observed with respective average values of $99.4 \mu \mathrm{g} / \mathrm{m}^{3}$, $15.8 \mu \mathrm{g} / \mathrm{m}^{3}, 4.5 \mu \mathrm{g} / \mathrm{m}^{3}$ and 29.7 at Bhimtal, while $202 \mu \mathrm{g} /$ $\mathrm{m}^{3}, 29.2 \mu \mathrm{g} / \mathrm{m}^{3}, 12.2 \mu \mathrm{g} / \mathrm{m}^{3}$ and $58.9 \mu \mathrm{g} / \mathrm{m}^{3}$ at Pantnagar. Higher summer values at Bhimtal could be attributed to the vertical movement of pollutants due to convective motions formed in the valley region. In contrast, Pantnagar 
exhibited higher values in winter that could be associated with the low planetary boundary layer, low temperature and stable atmospheric conditions. Percentage contributions of OC, EC and TCA to total TSP were for almost $15.5 \%, 4.5 \%$ and 29.5 at Bhimtal and $15 \%, 6 \%$ and $30 \%$ at Pantnagar, respectively. Among the eight carbon fractions, OC2 and OC 3 accounted for $29 \%$ and $21 \%$ of TC at Bhimtal, respectively, while EC1 and OC2 contributed for $26 \%$ and $25 \%$ of TC at Pantnagar, respectively. Char-EC and soot-EC showed almost similar seasonal patterns as that of OC and EC where char contributed significantly as 90\% and $88.5 \%$ to total EC at Bhimtal and Pantnagar, respectively. The char/soot ratios at both sites indicated that carbonaceous aerosols were mainly derived from biomass and vegetative burning. Correlation analysis among carbonaceous components and meteorological parameters has been conducted, and results demonstrated that these parameters were weak to moderate positively correlated with PBL, T and SR at Bhimtal and, however, showed anticorrelation at Pantnagar with these parameters.

The present study is preliminary work in this region and could provide a basic understanding of carbonaceous aerosols, formation mechanisms and source attributions. It is noted that smaller sampling periods at two sampling sites are the limitation of the current study; therefore, future studies need a more extensive sampling campaign and long-term quantitative approach along with modelling tools for different size fractions of aerosols.

Acknowledgements The study was supported by Department of Science and Technology, Government of India, for providing financial support as an NPDF (SERB-NPDF 000872). Authors would like to thank Dr. B. S. Bisht, Director (Birla Institute of Applied Science, Bhimtal), Prof. H. S. Kushwaha (G.B.P. University of Agriculture and Technology, Pantnagar) and Dr. Shankar Agarwal (CSIR-NPL) for providing logistic supports at the sampling points. We are also thankful to Director, National Physical Laboratory for his encouragement and support.

\section{Compliance with ethical standards}

Conflict of interest The authors declare that they have no conflict of interest.

Open Access This article is licensed under a Creative Commons Attribution 4.0 International License, which permits use, sharing, adaptation, distribution and reproduction in any medium or format, as long as you give appropriate credit to the original author(s) and the source, provide a link to the Creative Commons licence, and indicate if changes were made. The images or other third party material in this article are included in the article's Creative Commons licence, unless indicated otherwise in a credit line to the material. If material is not included in the article's Creative Commons licence and your intended use is not permitted by statutory regulation or exceeds the permitted use, you will need to obtain permission directly from the copyright holder. To view a copy of this licence, visit http://creativecommons .org/licenses/by/4.0/.

\section{References}

1. Cao JJ, Lee SC, Ho KF et al (2004) Spatial and seasonal variations of atmospheric organic carbon and elemental carbon in Pearl River Delta Region, China. Atmos Environ 38:4447-4456. https ://doi.org/10.1016/j.atmosenv.2004.05.016

2. Han YM, Han ZW, Cao JJ et al (2008) Distribution and origin of carbonaceous aerosol over a rural high-mountain lake area, Northern China and its transport significance. Atmos Environ 42:2405-2414. https://doi.org/10.1016/j.atmosenv.2007.12.020

3. Gu J, Bai Z, Liu A et al (2010) Characterization of Atmospheric Organic Carbon and Element Carbon of PM2.5 and PM10 at Tianjin. China Aerosol Air Qual Res 10:167-176. https://doi. org/10.4209/aaqr.2009.12.0080

4. Zhang R, Tao J, Ho KF et al (2012) Characterization of atmospheric organic and elemental Carbon of PM2.5 in a typical semi-arid area of Northeastern China. Aerosol Air Qual Res 12:792-802. https://doi.org/10.4209/aaqr.2011.07.0110

5. Bao M, Cao F, Chang Y et al (2017) Characteristics and origins of air pollutants and carbonaceous aerosols during wintertime haze episodes at a rural site in the Yangtze River Delta, China. Atmos Pollut Res 8:900-911. https://doi.org/10.1016/j. apr.2017.03.001

6. Wang $X$, Wang F, Feng $T$ et al (2020) Occurrence, sources and seasonal variation of PM2.5 carbonaceous aerosols in a water level fluctuation zone in the Three Gorges Reservoir. China Atmos Pollut Res 11:1249-1257. https://doi.org/10.1016/j. apr.2020.04.014

7. Grivas G, Cheristanidis S, Chaloulakou A (2012) Elemental and organic carbon in the urban environment of Athens. Seasonal and diurnal variations and estimates of secondary organic carbon. Sci Total Environ 414:535-545. https://doi.org/10.1016/j. scitotenv.2011.10.058

8. Zhan C, Zhang J, Zheng J et al (2019) Characterization of carbonaceous fractions in PM2.5 and PM10 over a typical industrial city in Central China. Environ Sci Pollut Res 26:1685516867. https://doi.org/10.1007/s11356-017-9970-9

9. Yan F, Wang P, Kang S et al (2020) High particulate carbon deposition in Lhasa-a typical city in the Himalayan-Tibetan Plateau due to local contributions. Chemosphere 247:125843. https://doi.org/10.1016/j.chemosphere.2020.125843

10. Murillo JH, Rojas Marin JF, Roman SR et al (2013) Temporal and spatial variations in organic and elemental carbon concentrations in PM10/PM2.5 in the metropolitan area of Costa Rica. Central Am Atmos Pollut Res 4:53-63. https://doi.org/10.5094/ APR.2013.006

11. Thuy NTT, Dung NT, Sekiguchi K et al (2018) Mass concentrations and Carbonaceous Compositions of PM0.1, PM2.5, and PM10 at Urban Locations of Hanoi. Vietnam Aerosol Air Qual Res 18:1591-1605. https://doi.org/10.4209/aaqr.2017.11.0502

12. Watson JG (2002) Visibility: science and regulation. J Air Waste Manag Assoc 52:628-713. https://doi.org/10.1080/10473 289.2002.10470813

13. Cao JJ, Lee SC, Ho KF et al (2006) Characterization of roadside fine particulate carbon and its eight fractions in Hong Kong. Aerosol Air Qual Res 6:106-122. https://doi.org/10.4209/ aaqr.2006.06.0001

14. Li B, Zhang J, Zhao Y et al (2015) Seasonal variation of urban carbonaceous aerosols in a typical city Nanjing in Yangtze River Delta, China. Atmos Environ 106:223-231. https://doi. org/10.1016/j.atmosenv.2015.01.064

15. Arhami M, Shahne MZ, Hosseini V et al (2018) Seasonal trends in the composition and sources of PM2.5 and carbonaceous aerosol in Tehran. Iran Environ Pollut 239:69-81. https://doi. org/10.1016/j.envpol.2018.03.111 
16. Grabowsky J, Streibel T, Sklorz M et al (2011) Hyphenation of a carbon analyzer to photo-ionization mass spectrometry to unravel the organic composition of particulate matter on a molecular level. Anal Bioanal Chem 401:3153-3164. https:// doi.org/10.1007/s00216-011-5425-1

17. Zhu C-S, Cao J-J, Tsai C-J et al (2014) Comparison and implications of PM2.5 carbon fractions in different environments. Sci Total Environ 466-467:203-209. https://doi.org/10.1016/j. scitotenv.2013.07.029

18. Cao JJ, Lee SC, Chow JC et al (2007) Spatial and seasonal distributions of carbonaceous aerosols over China. J Geophys Res 112:D22S11. https://doi.org/10.1029/2006JD008205

19. Guo Y (2016) Size distribution characteristics of carbonaceous aerosol in a rural location in northwestern China. Air Qual Atmos Health 9:193-200. https://doi.org/10.1007/s11869-015-0322-y

20. Cao JJ, Wu F, Chow JC et al (2005) Characterization and source apportionment of atmospheric organic and elemental carbon during fall and winter of 2003 in Xi'an. China, Atmos Chem Phys, p 11

21. Han YM, Lee SC, Cao JJ et al (2009) Spatial distribution and seasonal variation of char-EC and soot-EC in the atmosphere over China. Atmos Environ 43:6066-6073. https://doi.org/10.1016/j. atmosenv.2009.08.018

22. Zhu C-S, Chen C-C, Cao J-J et al (2010) Characterization of carbon fractions for atmospheric fine particles and nanoparticles in a highway tunnel. Atmos Environ 44:2668-2673. https://doi. org/10.1016/j.atmosenv.2010.04.042

23. Kim KH, Sekiguchi K, Furuuchi M, Sakamoto K (2011) Seasonal variation of carbonaceous and ionic components in ultrafine and fine particles in an urban area of Japan. Atmos Environ 45:1581-1590. https://doi.org/10.1016/j.atmosenv.2010.12.037

24. Han YM, Cao JJ, Lee SC et al (2010) Different characteristics of char and soot in the atmosphere and their ratio as an indicator for source identification in Xi'an, China. Atmos Chem Phys 10:595-607. https://doi.org/10.5194/acp-10-595-2010

25. Xu Z, Wen T, Li X et al (2015) Characteristics of carbonaceous aerosols in Beijing based on two-year observation. Atmos Pollut Res 6:202-208. https://doi.org/10.5094/APR.2015.024

26. Dinoi A, Cesari D, Marinoni A et al (2017) Inter-comparison of carbon content in PM2.5 and PM10 collected at five measurement sites in Southern Italy. Atmosphere 8:243. https://doi. org/10.3390/atmos8120243

27. Bisht DS, Dumka UC, Kaskaoutis DG et al (2015) Carbonaceous aerosols and pollutants over Delhi urban environment: temporal evolution, source apportionment and radiative forcing. Sci Total Environ 521-522:431-445. https://doi.org/10.1016/j.scito tenv.2015.03.083

28. Srivastava AK, Ram K, Pant P et al (2012) Black carbon aerosols over Manora Peak in the Indian Himalayan foothills: implications for climate forcing. Environ Res Lett 7:014002. https://doi. org/10.1088/1748-9326/7/1/014002

29. Kumar A, Attri AK (2016) Biomass combustion a dominant source of carbonaceous aerosols in the ambient environment of Western Himalayas. Aerosol Air Qual Res 16:519-529. https ://doi.org/10.4209/aaqr.2015.05.0284

30. Rajput P, Sarin M, Kundu SS (2013) Atmospheric particulate matter (PM2.5), EC, OC, WSOC and PAHs from NE-Himalaya: abundances and chemical characteristics. Atmos Pollut Res 4:214-221. https://doi.org/10.5094/APR.2013.022

31. Sandeep K, Negi RS, Panicker AS et al (2020) Characteristics and variability of Carbonaceous Aerosols over a Semi Urban Location in Garhwal Himalayas. Asia-Pacific J Atmos Sci 56:455-465. https://doi.org/10.1007/s13143-019-00158-1

32. Census of India 2011, Uttarakhand Series-06 Part XII-A District Census Handbook. https://censusindia.gov.in/2011census/ dchb/0511_PART_A_DCHB_NAINITAL.pdf
33. Banerjee T, Srivastava RK (2011) Evaluation of environmental impacts of Integrated Industrial Estate-Pantnagar through application of air and water quality indices. Environ Monit Assess 172:547-560. https://doi.org/10.1007/s10661-010-1353-3

34. Ali K, Panicker AS, Beig G et al (2016) Carbonaceous aerosols over Pune and Hyderabad (India) and influence of meteorological factors. J Atmos Chem 73:1-27. https://doi.org/10.1007/ s10874-015-9314-4

35. Rastogi N, Sarin MM (2009) Quantitative chemical composition and characteristics of aerosols over western India: One-year record of temporal variability. Atmos Environ 43:3481-3488. https://doi.org/10.1016/j.atmosenv.2009.04.030

36. Novakov T, Menon S, Kirchstetter TW et al (2005) Aerosol organic carbon to black carbon ratios: analysis of published data and implications for climate forcing. J Geophys Res 110:D21205. https://doi.org/10.1029/2005JD005977

37. Chow JC, Watson JG, Chen L-WA et al (2007) The IMPROVE_A temperature protocol for Thermal/Optical Carbon analysis: maintaining consistency with a long-term database. J Air Waste Manag Assoc 57:1014-1023. https://doi. org/10.3155/1047-3289.57.9.1014

38. Banerjee T, Singh SB, Srivastava RK (2011) Development and performance evaluation of statistical models correlating air pollutants and meteorological variables at Pantnagar, India. Atmos Res 99:505-517. https://doi.org/10.1016/j.atmos res.2010.12.003

39. Ram K, Sarin MM (2011) Day-night variability of EC, OC, WSOC and inorganic ions in urban environment of IndoGangetic Plain: Implications to secondary aerosol formation. Atmos Environ 45:460-468. https://doi.org/10.1016/j.atmos env.2010.09.055

40. Tiwari S, Srivastava AK, Bisht DS et al (2013) Assessment of carbonaceous aerosol over Delhi in the Indo-Gangetic Basin: characterization, sources and temporal variability. Nat Hazards 65:1745-1764. https://doi.org/10.1007/s11069-012-0449-1

41. Cao J (2003) Characteristics of carbonaceous aerosol in Pearl River Delta Region, China during 2001 winter period. Atmos Environ 37:1451-1460. https://doi.org/10.1016/S1352 -2310(02)01002-6

42. Kumar P, Yadav S (2016) Seasonal Variations in Water Soluble Inorganic lons, $\mathrm{OC}$ and EC in PM10 and PM>10 Aerosols over Delhi: Influence of Sources and Meteorological Factors. Aerosol Air Qual Res 16:1165-1178. https://doi.org/10.4209/ aaqr.2015.07.0472

43. Toro Araya R, Flocchini R, Morales Segura RGE, Leiva Guzmán MA (2014) Carbonaceous aerosols in fine particulate matter of Santiago Metropolitan Area, Chile. Sci World J 2014:1-12. https ://doi.org/10.1155/2014/794590

44. Ram K, Sarin MM, Hegde P (2008) Atmospheric abundances of primary and secondary carbonaceous species at two high-altitude sites in India: Sources and temporal variability. Atmos Environ 42:6785-6796. https://doi.org/10.1016/j.atmos env.2008.05.031

45. Hegde P, Kawamura K (2012) Seasonal variations of water-soluble organic carbon, dicarboxylic acids, ketocarboxylic acids, and a-dicarbonyls in Central Himalayan aerosols. Atmos Chem Phys 12:6645-6665. https://doi.org/10.5194/acp-12-6645-2012

46. Sagar R, Kumar B, Dumka UC et al (2004) Characteristics of aerosol spectral optical depths over Manora Peak: A high-altitude station in the central Himalayas: AEROSOL PROPERTIES OVER MANORA PEAK. J Geophys Res 109:n/a-n/a. https://doi. org/10.1029/2003JD003954

47. Shi G, Peng X, Liu J et al (2016) Quantification of long-term primary and secondary source contributions to carbonaceous aerosols. Environ Pollut 219:897-905. https://doi.org/10.1016/j. envpol.2016.09.009 
48. Feng Y, Chen Y, Guo H et al (2009) Characteristics of organic and elemental carbon in PM2.5 samples in Shanghai. China Atmos Res 92:434-442. https://doi.org/10.1016/j.atmosres.2009.01.003

49. Husain L, Khan AJ, Ahmed T et al (2008) Trends in atmospheric elemental carbon concentrations from 1835 to 2005. J Geophys Res 113:D13102. https://doi.org/10.1029/2007JD009398

50. Carrico CM, Bergin MH, Shrestha AB et al (2003) The importance of carbon and mineral dust to seasonal aerosol properties in the Nepal Himalaya. Atmos Environ 37:2811-2824. https://doi. org/10.1016/S1352-2310(03)00197-3

51. Tanner RL, Bairai ST, Olszyna KJ et al (2005) Diurnal patterns in PM2.5 mass and composition at a background, complex terrain site. Atmos Environ 39:3865-3875. https://doi.org/10.1016/j. atmosenv.2005.03.014

52. Cao J-J, Zhu C-S, Tie X-X et al (2013) Characteristics and sources of carbonaceous aerosols from Shanghai, China. Atmos Chem Phys 13:803-817. https://doi.org/10.5194/acp-13-803-2013

53. Kaushal D, Kumar A, Yadav S et al (2018) Wintertime carbonaceous aerosols over Dhauladhar region of North-Western Himalayas. Environ Sci Pollut Res 25:8044-8056. https://doi. org/10.1007/s11356-017-1060-5
54. Li P, Wang Y, Li T et al (2015) Characterization of carbonaceous aerosols at Mount Lu in South China: implication for secondary organic carbon formation and long-range transport. Environ Sci Pollut Res 22:14189-14199. https://doi.org/10.1007/s1135 6-015-4654-9

55. Srivastava P, Naja M (2020) Characteristics of carbonaceous aerosols derived from long-term high-resolution measurements at a high-altitude site in the central Himalayas: radiative forcing estimates and role of meteorology and biomass burning. Environ Sci Pollut Res. https://doi.org/10.1007/s11356-020-11579-1

56. Li P, Han B, Huo J et al (2012) Characterization, Meteorological Influences and Source Identification of Carbonaceous Aerosols during the Autumn-winter Period in Tianjin, China. Aerosol Air Qual Res 12:283-294. https://doi.org/10.4209/aaqr.2011.09.0140

Publisher's Note Springer Nature remains neutral with regard to jurisdictional claims in published maps and institutional affiliations. 